\title{
EDITORIAL
}

\section{A Scientific Approach to Special Education}

\author{
Kevin Wheldall and Mark Carter \\ Macquarie University Special Education Centre, Macquarie University, Sydney, Australia
}

Science is nothing but trained and organised common sense. (Thomas Huxley)

If this aphorism from the famous biologist is true, then we might argue that trained and organised common sense in education could be in short supply, because there is very little science to support it! Of course, this proposition does not follow logically: even if all policemen were six feet tall, it would not mean that all those who are six feet tall are policemen. Inductive reasoning aside, however, what we would argue is that both science and trained and organised common sense seem to be lacking in education, and that these two facts are not unrelated. In this special issue, we examine the case for 'A Scientific Approach to Special Education' specifically.

Over recent decades, the fashion in educational research has moved almost inexorably from quantitative to qualitative methodologies while positivism has largely given way to relativism (Wheldall, 2006). It is almost as if we have been witnessing the slow death of scientific research in education. Mark Twain once quipped that the reports of his death had been greatly exaggerated and, perhaps, so it is with educational research. Or are we witnessing instead a valiant deathbed recovery? Whatever the case, there is certainly increasing interest and talk about the idea of education being more scientifically based. The reports of recent federal government inquiries into Literacy (Teaching reading, Department of Education, Science and Training, 2005) and the Academic Standards of School Education (Quality of school education, Senate Standing Committee on Employment, Workplace Relations and Education, 2007) are good examples. The latter report urges as its fifth recommendation, for example:

that the Minister take up with Universities Australia the need to encourage a more rigorous and evidence-based approach to the preparation of trainee teachers in regard to literacy and mathematics method.

The extent to which the rhetoric is matched by subsequent government behaviour, however, is one of the themes picked up in the editorial article that prefaces this issue by Carter and Wheldall, alongside explorations of the degree to which teachers keep 


\section{Editorial}

themselves informed of contemporary evidence-based best practice and the nature of the instructional model often provided to them during training by education faculties. We also consider the value of the What Works Clearinghouse (WWC) and whether we can place much faith in its pronouncements on the efficacy of specific programs and practices. Given the relative lack of true 'gold standard' experimental research in education, an alternative sliding scale, by which to evaluate the quality of the evidence that is available, is proposed.

In his contribution, Kerry Hempenstall provides an example of the sort of research evidence that is all too rare in education. Although not offering a 'gold standard' fully randomised experimental-control group design, he does provide what might be regarded as the next best thing, an efficacy study using a wait-list-control group design. In his evaluation of the efficacy of the program Corrective Reading, he compared the gains made by the students undertaking the program with those of a control group of students who were to be admitted to the program as part of the next intake. In addition to the wait-list element of the design, he also makes good use of the pre-test data as a covariate to reduce error variance attributable to differences among students prior to the intervention, thereby increasing the sensitivity of the statistical procedures to detect differences between the groups. Yet another welcome design feature was his decision to employ a series of dependent variables measuring a variety of literacy features including phonological awareness, word attack skills and spelling, as well as picture naming and digit span. Finally, and very importantly, he provides effect size information as an aid to understanding the educational importance of his findings. As a result of his study, Hempenstall was able to demonstrate that the experimental group students made both statistically significant and educationally significant gains compared with their peers in the waitlist control group. This is very much the sort of evidence educationists should be heeding when making educational decisions regarding what teaching materials to employ.

Of course, fully randomised experimental, or even quasi-experimental designs such as wait-list control studies, are not always possible in special education where the specific disability under scrutiny occurs only rarely in the population. In such cases, another form of quasi-experimental design offers a possible alternative in the form of single subject and small $\mathrm{N}$ research methodology, as mentioned by Carter and Wheldall. Jeff Sigafoos and his colleagues provide an excellent example of such an approach, in their article. As argued by Sigafoos and colleagues, teachers not only need to be able to identify an intervention with a high probability of success but also need to be able to monitor the effectiveness of intervention for the individual under classroom conditions. Such monitoring also enables the teacher to make adjustments to the intervention based on idiosyncratic responses of the learner. The type of small $\mathrm{N}$ research design exemplified in this article is ideally suited to this purpose.

In the following three articles in the series that comprises this special issue, the scientific evidence supposedly underpinning three current, heavily promoted approaches to special educational practice is reviewed. First, Jennifer Stephenson 
and Kevin Wheldall critically examine the claims made for the Dore program. These claims do not appear to accord well with the existing published research and there are major questions whether the Dore program makes conceptual sense in the light of current scientific theory. They conclude that 'none of the necessary desiderata to substantiate claims for a cure are met by the available scientific evidence for the efficacy of the Dore program'.

Han Leong and Mark Carter subsequently review the scientific evidence supporting the widely practised but controversial sensory integration therapy. While perceptual motor programs, like Dore, have re-invented themselves over the years, sensory integration has obscured the accumulated evidence suggesting it is ineffective, in part, by moving on to new client groups. In reviewing the most recent evidence on sensory integration, Leong and Carter find that the focus has now largely shifted to autism. Consistent with previous reviews, they find a deeply flawed body of research providing no consistent or convincing evidence to support the continued application of the technique. The fact that sensory integration has survived around 40 years (despite the evidence) might lead some to conclude that there must be something to it. If this line of reasoning is accepted, homeopathy and astrology, both of which have much longer traditions, would also have to be readily accepted as validated practices. We think not.

The WWC review of the Fast ForWord ${ }^{\circledR}$ program is then examined by Genevieve McArthur. Carter and Wheldall, in their editorial article, provided two clear examples of failures of process by the WWC and McArthur provides a third example, showing how WWC's evaluation of Fast ForWord ${ }^{\circledR}$ is flawed and making several suggestions for improvement. In particular, McArthur's suggestion that WWC reports be submitted for independent peer review is worthy of consideration. We would stress that we are very supportive of the basic idea of objectively synthesising educational research. In fact, filtering and synthesis of empirical research has the potential to provide exactly the sort of guidance that educational systems and teachers desperately need. Unfortunately, on the available evidence, the WWC is poorly implemented at this time and many of the resulting recommendations should probably be considered unsafe.

Foreman and Arthur-Kelly, in their article for this issue, then examine the thorny issue of the inclusion of students with disabilities into mainstream settings from a variety of perspectives: social justice principles, legislation and research findings. Foreman and Arthur-Kelly remind us of both the problems of conducting research in some areas of education and that educational decision making is ultimately influenced by a wide range of factors. They propose an agenda of future research questions to help further the debate.

In the editorial article, Carter and Wheldall raise the general issue of the inherent fallibility of human perception and perils of substituting personal experience for objective and scientific research. Greg Yates extends this line of argument in his contributed article examining roadblocks to scientific thinking in educational decision making. He argues persuasively that everyday thinking, which serves us 


\section{Editorial}

well for much of our immediate personal day-to-day decision making, is quite different from the sort of long-term scientific thinking that is needed to make strategic decisions under conditions of uncertainty and ambiguity.

Finally, we are privileged to be able to include in this special issue a contribution from the eminent American educationist, Siegfried 'Zig' Engelmann, the 'godfather of Direct Instruction'. In his article, Zig argues that educational research typically goes beyond the evidence and questions the methods employed. Moreover, 'researchers lack detailed information about teaching'. The effect of this is that even worthy attempts at change, such as recent research-based reading initiatives, may lead to unwarranted conclusions being drawn. It could be argued that we have also witnessed similar problems in Australia whereby so-called research-based reading programs merely pay lip-service to the carefully enunciated desiderata for effective reading instruction conveyed in the report of the National Inquiry into the Teaching of Reading (Department of Education, Science and Training, 2005). Zig subsequently outlines his own preferred method:

the most relevant type of design would be one that fully implements a highly successful program, records times and student mastery. Then specific details of the program are changed and the difference in performance (if any) is noted. It is very revealing that this design has never (to the best of my knowledge) been used in research.

It might appear that we are being unduly pessimistic about the scientific status of research in special education but this is not the case. While we may have spent more time examining what is wrong with scientific research in special education, we are actually impressed by the increasing rigour demanded of, for example, demonstrations of efficacy of programs and interventions. In other words, we think that the critical edge of much of the commentary in this special issue is a healthy sign of the discipline coming of age.

\section{References}

Department of Education, Science and Training. (2005). Teaching reading. Canberra: Department of Education, Science and Training.

Senate Standing Committee on Employment, Workplace Relations and Education. (2007). Quality of school education. Canberra: Commonwealth of Australia.

Wheldall, K. (2006). When will we ever learn? In K. Wheldall (Ed.), Developments in educational psychology: How far have we come in 25 years? (pp. 1-12). London: Routledge. 